\title{
Differing deregulation of EGFR and downstream proteins in primary colorectal cancer and related metastatic sites may be clinically relevant
}

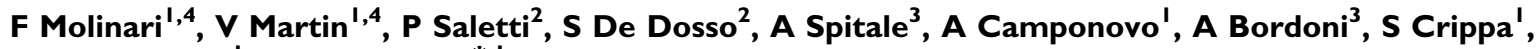 \\ L Mazzucchelli' and M Frattini*,I
}

IInstitute of Pathology, Locarno, Switzerland; ${ }^{2}$ Oncology Institute of Southern Switzerland, Ospedale San Giovanni, Bellinzona, Switzerland; ${ }^{3}$ Ticino Cancer Registry, Locarno, Switzerland

\begin{abstract}
Cetuximab and panitumumab efficacy in metastatic colorectal cancer (mCRC) may be influenced by EGFR gene status and/or deregulation of its downstream signalling proteins detected in primary tumour. However, metastasis might have different molecular patterns with respect to primary tumour, possibly affecting the prediction of EGFR-targeted therapy efficacy. We analysed primary tumour and metastasis in $38 \mathrm{mCRC}$ patients. Twelve cases were cetuximab/panitumumab treated. EGFR gene status and protein expression were investigated through fluorescent in situ hybridisation and immunohistochemistry (IHC), K-Ras/BRAF mutations by sequencing and PTEN expression by IHC. We observed EGFR gene deregulation in 25 out of 36 primary tumours and 29 out of 36 metastases, K-Ras mutations in 16 out of 37 cancers and in 15 out of 37 metastases, BRAF mutations in 2 out of 36 cancers and 2 out of 36 metastases and PTEN loss in 8 out of 38 cancers and 12 out of 38 metastases. For the first time in literature, we show that primary colorectal cancer and paired metastasis may exhibit difference with respect to EGFR pathway deregulation mechanisms possibly implying a different response to cetuximab or panitumumab treatment. The investigation of treated patients confirms this hypothesis. We therefore suggest that the analysis of metastatic lesion should be considered in patient management as well as in designing future clinical trials aimed to investigate the effect of anti-EGFR monoclonal antibodies in the treatment of mCRC. British Journal of Cancer (2009) 1 00, 1087- 1094. doi:I0.1038/sj.bjc.6604848 www.bjcancer.com

Published online 17 March 2009

(c) 2009 Cancer Research UK
\end{abstract}

Keywords: colorectal cancer; epidermal growth factor receptor; K-Ras; BRAF; PTEN

Epidermal growth factor receptor (EGFR) is a member of the transmembrane tyrosine kinase receptor family ErbB, involved in controlling cell growth, differentiation and proliferation by triggering both the Ras-RAF-MAP kinase pathway and the PI3K-PTEN-Akt pathway (Ciardiello and Tortora, 2008). Epidermal growth factor receptor constitutive activation leads to malignant transformation, angiogenesis and metastatic dissemination. Owing to its relevance in cancer development, EGFR represents a natural molecular target for a new class of anticancer drugs. In colorectal cancer, where EGFR is overexpressed in a consistent number of cases, cetuximab and panitumumab, two monoclonal antibodies (MoAbs) that recognise the extracellular domain of the receptor leading to its inactivation, have entered in clinical practice for the treatment of metastatic disease (Ciardiello and Tortora, 2008). Both drugs, however, are effective only in approximately $10 \%$ of metastatic colorectal cancer (mCRC) patients (Ciardiello and Tortora, 2008), underscoring therefore the need of simple tests able to predict a response to these agents.

\footnotetext{
*Correspondence: Dr M Frattini; E-mail: milo.frattini@ti.ch

${ }^{4}$ These authors contributed equally to this work as first authors.

Received 17 September 2008; revised 24 November 2008; accepted

I December 2008; published online 17 March 2009
}

To date, several studies demonstrated that EGFR protein expression detected by immunohistochemistry (IHC) in cancer specimens is insufficient to determine response to cetuximab therapy (reported in Chung et al, 2005). By contrast, EGFR gene copy number gain (CNG, due to either polysomy or gene amplification), evaluated by fluorescent in situ hybridisation (FISH), seems to be a better predictive marker for anti-EGFR MoAb sensitivity (Lièvre et al, 2005; Moroni et al, 2005; Cappuzzo et al, 2007; Frattini et al, 2007; Sartore-Bianchi et al, 2007; Personeni et al, 2008), whereas the presence of $K$-Ras mutations and/or loss of PTEN protein expression by IHC predicts resistance to these drugs (Lièvre et al, 2005; Moroni et al, 2005; Benvenuti et al, 2007; Cappuzzo et al, 2007; Di Fiore et al, 2007; Frattini et al, 2007; Khambata-Ford et al, 2007; Sartore-Bianchi et al, 2007; De Roock et al, 2008; Lièvre et al, 2008).

All these data have been obtained by analysing clinical response in mCRC patients with regard to molecular features detected in primary tumour. It is possible, however, that primary tumour and paired metastatic lesions might be different at the molecular marker expression or gene status levels and that these differences may affect the clinical significance of a predictive test. In this contest, it is noteworthy that the few previously published studies on this issue focused almost exclusively on the rather unreliable evaluation of EGFR expression by IHC (McKay et al, 2002; Ooi et al, 2004; Scartozzi et al, 2004; Bralet et al, 2005; Italiano et al, 2005; 
Bibeau et al, 2006; Cappuzzo et al, 2007). The aim of this study is to analyse molecular alterations predictive for anti-EGFR therapies response, such as EGFR gene status, $K-R a s$ and $B R A F$ mutations, and PTEN protein expression, in primary tumour and synchronous or metachronous metastasis. In patients treated with MoAbs against EGFR, the molecular and clinical data were matched.

\section{PATIENTS AND METHODS}

\section{Patient population and treatment regimens}

The analysis was conducted in 38 patients who underwent primary surgery for colorectal cancer presenting with synchronous or developing metachronous metastasis and who were identified from the database of the local cancer registry (www.ti.ch/tumori). Tissue specimens were available for both primary tumour and metastasis, and they were evaluated at the local institute of pathology (www.ti.ch/icp) after fixation in $4 \%$ neutral buffered formalin. All tumours were adenocarcinomas. Twelve patients were treated with cetuximab- or panitumumab-based regimens at the Oncology Institute of Southern Switzerland. With the exception of one patient who received cetuximab as a frontline therapy, the others had failed at least one prior chemotherapy regimen based on irinotecan. For the last patients, the MoAbs were administered in combination with irinotecan given at the same dose and schedule as previously used. Treatment was continued until progressive disease (PD) or toxicity occurred, according to the standard criteria (Therasse et al, 2000) or to specific trial guidelines. Patients evaluated in this study were selected based on evidence that treatment outcome could be attributable only to administration of either panitumumab or cetuximab.

\section{Clinical evaluation and response criteria}

The response was assessed every 6 weeks with radiological examination (computerised tomodensitometry or magnetic resonance imaging). The Response Evaluation Criteria in Solid Tumors were adopted for evaluation and classified as partial response (PR), as stable disease (SD) or PD. Patients with SD or PD were defined as non-responders (NRs) (Therasse et al, 2000). Response to therapy was also evaluated retrospectively by independent radiologists.

\section{Molecular analyses}

All formalin-fixed paraffin-embedded tumour blocks were reviewed for quality and tumour content, and a single representative tumour block from each case, containing at least $70 \%$ of neoplastic cells, was selected for immunohistochemical, cytogenetic and molecular analyses. Tumour macrodissection was performed in tumour blocks containing less than $70 \%$ of neoplastic cells (to reduce the presence of non-neoplastic tissues). Genomic DNA was extracted using the QIAamp Mini kit (Qiagen, Chatsworth, CA, USA) according to the manufacturer's instructions.

Immunohistochemistry: Epidermal growth factor receptor protein expression was evaluated on $3 \mu \mathrm{m}$ thick tissue sections using the EGFR pharmDx assay (Dako Cytomation, Carpinteria, CA, USA) according to the manufacturer's instructions, as reported earlier (Frattini et al, 2007). Tissue samples were considered EGFR positive if at least $1 \%$ of malignant cells were stained for EGFR. As external controls, we used those included in the kit.

PTEN protein expression status was performed according to the literature (Saal et al, 2005; Frattini et al, 2007). PTEN protein expression was detected mainly at the cytoplasmic level, although occasional nuclear positivity was present. We considered PTEN negative those specimens showing a strong reduction or absence of immunostaining in at least $50 \%$ of cells, as compared with either the internal (normal colon mucosa) or external (normal endometrium) control.

All immunohistochemical analyses were performed by two independent observers ( $\mathrm{SC}$ and $\mathrm{LM}$ ) giving superimposable results. The evaluation was performed without knowledge of clinical evaluation of the results of other analyses.

Fluorescent in situ hybridisation: EGFR gene status evaluation was performed on $3 \mu \mathrm{m}$ thick tissue sections that were treated using Paraffin Pretreatment kit II (Vysis, Downer's Grove, IL, USA) according to the manufacturer's instructions. Dual-colour FISH assay was performed using LSI EGFR/CEP7 probes (Vysis), as mentioned earlier (Frattini et al, 2007). The LSI EGFR probe is labelled in SpectrumOrange and covers an approximately $300 \mathrm{~kb}$ region that contains the entire EGFR gene at $7 \mathrm{p} 12$. The CEP7 probe, labelled in SpectrumGreen, hybridises to the $\alpha$-satellite DNA located at the centromere of chromosome 7 (7p11.1-q11.1). To overcome the problem of tissue heterogeneity, we evaluated 10 different tumour areas and at least 10 representative nuclei from each area. Overall, a total of 100 cells for each patient were scored. For cases in which only a biopsy was available, we evaluated all the analysable nuclei. Cases showing two chromosome 7 (Chr7) in more than $50 \%$ of cells were classified as disomic. Tumour samples with an aberrant number of Chr7, defined as more than four in at least $50 \%$ of cells, were classified as markedly polysomic. Specimens with a ratio of more than 2 between EGFR gene and Chr7 centromere signals in at least $10 \%$ of cells were classified as carrying EGFR gene amplification.

The EGFR gene status evaluation was performed by two independent observers (FM and VM) giving superimposable results. The evaluation was performed without the knowledge of clinical evaluation of the results of other analyses.

K-Ras and BRAF mutational status: We searched for K-Ras point mutations in codons 12 and 13, two hotspots that cumulatively include more than $95 \%$ of mutations in this gene, as already reported (Frattini et al, 2007). BRAF mutations were investigated in exon 15 , in which more than $95 \%$ of $B R A F$ point mutations occur, as reported earlier (Frattini et al, 2004). All samples were subjected to automated sequencing by ABI PRISM 3100 (Applied Biosystems, Foster City, CA, USA) and analysed with Chromas software (http://www.technelysium.com.au/chromas.html). Each sequence reaction was performed at least twice, starting from independent PCRs. In each case, the detected mutation was confirmed in the sequence as sense and antisense strands.

\section{Statistical analyses}

The association between primary tumours and related metastatic sites for EGFR gene status, $B R A F$ and $K$-Ras mutational status, and PTEN protein expression was evaluated by means of the Cohen's $\kappa$-test, appropriate for the assessment of the concordance between two categorical measurements of the same individual. A moderate and good agreement was defined as the coefficient was $0.41 \leqslant \mathrm{k} \leqslant 0.60$ and $0.61 \leqslant \mathrm{k} \leqslant 0.80$, respectively (Landis and Koch, 1977). All statistical tests were two sided. Significance levels were set at $P \leqslant 0.05$. All statistical analyses were carried out using the SAS System V 9.1 Software (SAS Institute Inc., Cary, NC, USA).

\section{RESULTS}

\section{Patient characteristics}

Patient characteristics are summarised in Table 1. Thirty-eight patients, 24 men (63\%) and 14 women (37\%), were included. The 
Table I Clinicopathological characteristics

\begin{tabular}{|c|c|c|}
\hline Patient characteristics $(N=38)$ & Number of cases & Percentage (\%) \\
\hline \multicolumn{3}{|l|}{ Age } \\
\hline$\leqslant 60$ years & 9 & 24 \\
\hline$>60$ years & 29 & 76 \\
\hline \multicolumn{3}{|l|}{ Gender } \\
\hline Male & 24 & 63 \\
\hline Female & 14 & 37 \\
\hline \multicolumn{3}{|l|}{ Tumour location } \\
\hline Proximal colon & 14 & 37 \\
\hline Distal colon & 15 & 39 \\
\hline Rectum & 9 & 24 \\
\hline \multicolumn{3}{|l|}{ Grade } \\
\hline Well/moderate & 26 & 68 \\
\hline Poor & 12 & 32 \\
\hline \multicolumn{3}{|l|}{ TNM classification } \\
\hline $\mathrm{T} 2$ & 1 & 3 \\
\hline T3 & 21 & 55 \\
\hline T4 & 13 & 34 \\
\hline Unknown & 3 & 8 \\
\hline \multicolumn{3}{|l|}{ Metastasis site analysed } \\
\hline Peritoneal carcinomatosis & 2 & 5 \\
\hline Liver & 28 & 74 \\
\hline Lung & 3 & 8 \\
\hline Omenthum & 3 & 8 \\
\hline Brain & 2 & 5 \\
\hline \multicolumn{3}{|l|}{ Number of metastasis } \\
\hline Single & 19 & 50 \\
\hline Multiple & 19 & 50 \\
\hline \multicolumn{3}{|l|}{ Metastatic lesions } \\
\hline Synchronous & 25 & 66 \\
\hline Metachronous & 13 & 34 \\
\hline \multicolumn{3}{|l|}{ Primary tumour } \\
\hline Biopsy & 3 & 8 \\
\hline Resection & 35 & 92 \\
\hline \multicolumn{3}{|l|}{ Metastatic lesion } \\
\hline Biopsy & 15 & 39 \\
\hline Resection & 23 & 61 \\
\hline
\end{tabular}

median age at the time of diagnosis was 67 years (range from 48 to 94 years). Twenty-nine patients had a colon cancer (76\%, 14 patients in the right and 15 in the left/sigmoid colon) and nine carried a rectal cancer $(24 \%)$. All, but one, patients were stage pT3/T4. Twelve carcinomas (32\%) were classified as poorly differentiated and $26(68 \%)$ as well or moderately differentiated.

Samples from metastatic sites $(n=53)$ included 15 lymph nodes and 38 visceral metastases located in the liver ( 28 out of $38=74 \%$ ), lung ( 3 out of $38=8 \%$ ), omentum ( 3 out of $38=8 \%$ ), peritoneum ( 2 out of $38=5 \%$ ) and brain ( 2 out of $38=5 \%$ ). In 19 patients, distant metastasis was confined to one site, whereas 19 patients had multiple metastases. Metastases were synchronous in 25 cases and metachronous in the remaining 13 patients.

Twelve patients were treated with MoAbs against EGFR and clinical follow-up data were available in all cases. Cetuximab or panitumumab was administered in combination with chemotherapy as upfront therapy in one case, as second line in four cases, as third line in four cases and as fourth line in three cases. Two patients (17\%) achieved PR after cetuximab-based therapy (Table 2).

\section{EGFR protein expression}

All tumour samples showed a positive EGFR expression as detected by IHC. Overall, the same pattern of EGFR protein expression between primary tumour and related metastasis, either at distant sites or in lymph nodes, was observed in all cases $(\kappa=1$, $P<0.0001$ ) (Table 2).

\section{EGFR gene status}

Two cases were excluded due to inadequate fixation of tissue sample (nos. 8 and 24, Table 2). Of the 36 remaining cases, Chr7 loss was observed in $1(3 \%)$ primary tumour, Chr7 disomy in 10 (28\%) cases, Chr7 polysomy in $17(47 \%)$ and EGFR gene amplification in $8(22 \%)$ cases (Table 2). In metastatic sites, EGFR gene status was classified as Chr7 loss in $1(3 \%)$ case, Chr7 disomy in $6(17 \%)$, Chr7 polysomy in $21(58 \%)$ and EGFR gene amplification in $8(22 \%)$ cases (Table 2$)$. The same pattern between primary tumour and related distant metastasis was observed in 24 out of $36(67 \%)$ patients (Table 2). Among those who exhibited differences between cancer and metastatic specimens, a trend in favour of deregulation was observed in eight cases (from Chr7 disomy to polysomy in six cases and from Chr7 polysomy to gene amplification in two cases), whereas four patients showed gene amplification or Chr7 polysomy in primary cancer and Chr7 polysomy or disomy, respectively, in related distant metastatic sites (Figure 1). If we consider the cases showing either Chr7 polysomy or EGFR gene amplification as a single group, we observed differences in eight patients ( 8 out of $36=22 \%$ ), namely two cases with EGFR deregulation limited to primary tumour and six cases to the metastasis $(\kappa=0.49, P=0.0002)$, thus revealing a moderate level of agreement between the two sites. In seven cases with a different $E G F R$ gene status pattern between primary tumour and distant metastasis and for which a lymph node metastasis was available, the EGFR gene status in the lymph node lesion was similar to that in primary tumour in five cases and to distant metastasis in two cases (Table 2).

\section{K-Ras mutational status}

One case was excluded due to the bad quality of DNA (no. 24, Table 2). Sixteen primary tumours $(43 \%)$ carried a $K$-Ras point mutation, of which 13 occurred at codon 12 and 3 at codon 13 . Mutations at codon 12 predominantly involved the second base, with prevalence of the GcT (GGT $\rightarrow$ GcT, Gly $\rightarrow$ Ala, G12A) and GaT $(\mathrm{GGT} \rightarrow \mathrm{GaT}, \mathrm{Gly} \rightarrow \mathrm{Asp}, \mathrm{G12D})$ changes, in six and four cases, respectively, whereas one patient showed the 12GtT codon (GGT $\rightarrow$ $\mathrm{GtT}, \mathrm{Gly} \rightarrow \mathrm{Val}, \mathrm{G} 12 \mathrm{~V}$ ). Only one patient carried a $\mathrm{K}-\mathrm{Ras}$ mutation involving the first base of codon 12, leading to the $12 \mathrm{aGT}$ change (GGT $\rightarrow$ aGT, Gly $\rightarrow$ Ser, G12S). The mutations found at codon 13 corresponded to the classical transition $\mathrm{G} \rightarrow \mathrm{A}$ in the second base of the codon (GGC $\rightarrow \mathrm{GaC}$, Gly $\rightarrow$ Asp, G13D) (Table 2).

At metastatic lesions, we observed a $K$-Ras mutation in 15 patients. Overall, the same mutational pattern between primary tumour and related metastasis was observed in 34 out of $37(92 \%)$ patients (Table 2). Among those who exhibited differences between cancer and metastatic specimens, two patients had a point mutation limited to primary tumour (one case with a 12tGT change and one with a $13 \mathrm{GaC}$ change) and one case to the metastasis (GGT $\rightarrow \mathrm{tGT}$, Gly $\rightarrow$ Cys, G12C $(\kappa=0.83, P<0.0001))$ (Figure 2$)$.

Lymph node metastasis had a K-Ras mutational pattern corresponding to that observed in primary tumours.

\section{$B R A F$ mutational status}

Two cases were excluded due to the bad quality of DNA (nos. 8 and 24 , Table 2). The classical BRAF point mutation occurring at codon 600 , leading to the amino-acid change V600E, was observed in two 
Table 2 Immunohistochemical, cytogenetic and molecular data

\begin{tabular}{|c|c|c|c|c|c|c|c|c|c|c|c|c|c|c|c|c|}
\hline \multicolumn{4}{|c|}{ EGFR IHC } & \multicolumn{3}{|c|}{ EGFR FISH } & \multicolumn{3}{|c|}{ K-Ras } & \multicolumn{3}{|c|}{ BRAF } & \multicolumn{3}{|c|}{ PTEN IHC } & Clinical response \\
\hline 2 & + & NA & + & P & NA & D & GI2A & NA & GI2A & WT & NA & WT & - & NA & - & - \\
\hline 3 & + & + & + & $P$ & NV & $P$ & WT & WT & GI2C & WT & WT & WT & + & + & + & - \\
\hline 4 & + & NA & + & A & NA & P & GI2D & NA & GI2D & WT & NA & WT & - & NA & - & - \\
\hline 5 & + & + & + & $P$ & $\mathrm{P}$ & P & GI2A & GI2A & GI2A & WT & WT & WT & - & - & - & - \\
\hline 8 & + & NA & + & NV & NA & NV & WT & NA & WT & $N V$ & NA & NV & + & NA & - & - \\
\hline 9 & + & + & + & $P$ & $P$ & $P$ & GI3D & GI3D & GI3D & WT & WT & WT & + & + & + & - \\
\hline 10 & + & NA & + & A & NA & A & WT & NA & WT & WT & NA & WT & + & NA & + & - \\
\hline II & + & + & + & A & A & $\mathrm{P}$ & WT & WT & WT & WT & WT & WT & + & + & + & - \\
\hline 12 & + & NA & + & A & NA & A & WT & NA & WT & WT & NA & WT & + & NA & + & - \\
\hline 13 & + & NA & + & A & NA & A & WT & NA & WT & WT & NA & WT & + & NA & + & - \\
\hline 14 & + & NA & + & $P$ & NA & $P$ & WT & NA & WT & WT & NA & WT & + & NA & + & - \\
\hline 20 & + & + & + & $P$ & $\mathrm{P}$ & $P$ & GI2V & GI2V & GI2V & WT & WT & WT & + & + & + & - \\
\hline 21 & + & NA & + & $\mathrm{D}$ & NA & $P$ & WT & NA & WT & WT & NA & WT & + & NA & + & - \\
\hline 22 & + & + & + & $P$ & P & D & WT & WT & WT & WT & WT & WT & + & + & + & - \\
\hline 23 & + & + & + & D & D & $P$ & GI2A & GI2A & GI2A & WT & WT & WT & + & + & + & - \\
\hline 24 & + & NA & + & NV & NA & NV & NV & NA & NV & NV & NA & NV & + & NA & + & - \\
\hline 25 & + & + & + & D & D & D & WT & WT & WT & V600E & V600E & V600E & + & + & + & NR \\
\hline 26 & + & + & + & D & D & D & $G \mid 2 D$ & $G \mid 2 D$ & GI2D & WT & WT & WT & + & + & + & - \\
\hline 27 & + & + & + & D & $\mathrm{P}$ & $P$ & GI2A & GI2A & GI2A & WT & WT & WT & - & - & - & NR \\
\hline 28 & + & + & + & $P$ & NV & A & GI2A & GI2A & GI2A & WT & WT & WT & + & - & - & NR \\
\hline 29 & + & + & + & D & D & $P$ & GI2D & GI2D & GI2D & WT & WT & WT & + & + & + & NR \\
\hline 30 & + & NA & + & A & NA & A & WT & NA & WT & WT & NA & WT & + & NA & + & PR \\
\hline 31 & + & + & + & $P$ & $\mathrm{P}$ & $P$ & WT & WT & WT & V600E & V600E & V600E & + & - & - & $N R$ \\
\hline 32 & + & NA & + & D & NA & D & WT & NA & WT & WT & NA & WT & + & NA & + & NR \\
\hline
\end{tabular}

Abbreviations: $A=E G F R$ gene amplification; $D=$ chromosome 7 disomy; $L=$ chromosome 7 loss; $L N=$ lymph node metastases; $M=$ distant metastatic sites; $N A=$ not available $N R=$ non-responsive; $N V=$ not evaluable; $P R=$ partially responsive; $P=$ chromosome 7 polisomy; $T$ = primary tumour; $W T=$ wild-type; '+' $=$ positive expression; '-'= negative expression.

primary tumours ( 2 out of $36=6 \%$ ) and in the $2(6 \%)$ related metastatic lesions (Table 2). Overall, the same mutational pattern between primary tumour and related metastasis, either at distant sites or in lymph nodes, was observed in all cases $(\kappa=1, P<0.0001)$ (Table 2). In the two patients carrying a $B R A F$ mutation we did not detect any point mutation in the K-Ras gene (Table 2).

\section{PTEN protein expression}

PTEN protein expression could be evaluated in all tissue samples by IHC. Normal PTEN expression was documented in 30 out of 38 (79\%) primary tumour specimens, whereas a loss of PTEN was found in $8(21 \%)$ cases. In distant metastatic lesions, $26(68 \%)$ cases showed a normal PTEN expression, whereas 12 (32\%) cases were classified as PTEN negative. Overall, the same PTEN protein expression pattern between primary tumour and related metastasis was observed in 34 cases (89\%, Figure 3 ). Four cases with a normal expression of PTEN in primary tumour showed a complete loss of expression (nos. 8 and 36, Table 2) or a dramatical reduction of protein expression in related distant metastatic sites (nos. 28 and $31(\kappa=0.73, P<0.0001)$, Table 2, Figure 3$)$. Lymph node metastasis had a PTEN immunophenotype similar to that observed in distant metastatic specimens.

\section{Clinical response and relationship with molecular profile}

Twelve patients were treated with MoAbs against EGFR and clinical data were collected. Seven patients showed a molecular profile in the primary tumour superimposable with that observed in visceral metastases (Table 2). Of these seven patients, two experienced a PR to the drug and were characterised by CNG in EGFR gene status and absence of any alteration in the EGFR downstream pathways. Five patients were NRs and were characterised by the absence of either EGFR CNG or EGFR CNG plus an alteration occurring in one member of EGFR downstream pathways (K-Ras or PTEN) (Table 2).

In five patients, all NRs, the molecular profile in primary tumour and related distant metastatic sites was discordant. Out of these, four patients showed differences in either EGFR gene status or PTEN protein expression (two cases each, nos. 27 and 29, nos. 28 and 31 , respectively), but carried an additional mutation in the $K-R a s$ or $B R A F$ gene both in primary tumour and metastasis. The fifth patient (no. 36) showed loss of PTEN expression limited to the metastasis but with $E G F R$ CNG, and the absence of any additional alteration in downstream pathways both in primary tumour and metastasis (Table 2). 
Primary tumour

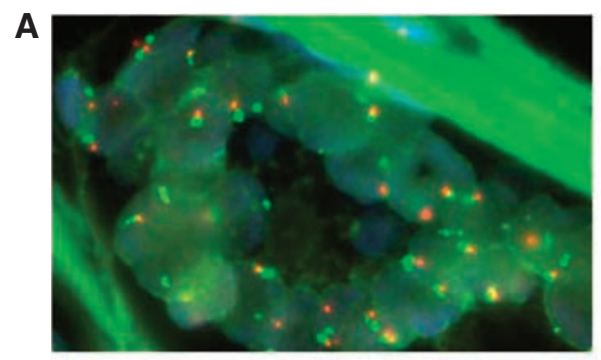

C

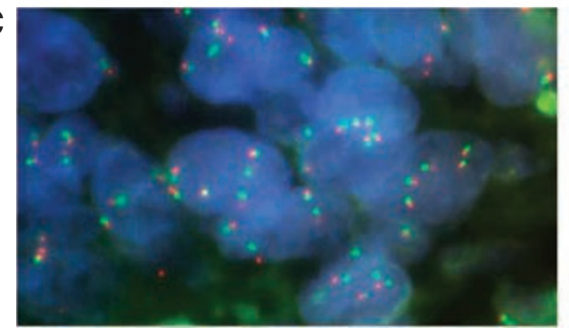

Metastasis
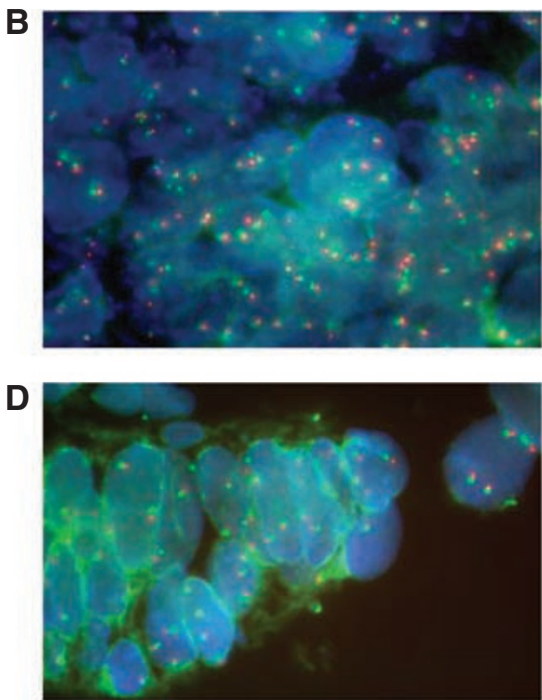

Figure I Representative examples of EGFR gene status differences in primary tumour and related metastasis in mCRC. Chr7 disomy in the primary tumour (A) and Chr7 polysomy in the paired metastasis (patient no. 6) (B); Chr7 polysomy in the primary tumour (C) and Chr7 disomy in the paired metastasis (patient no. 2) (D).

Primary Tumour

A $\quad A G C T G G T G G C G T A G G$

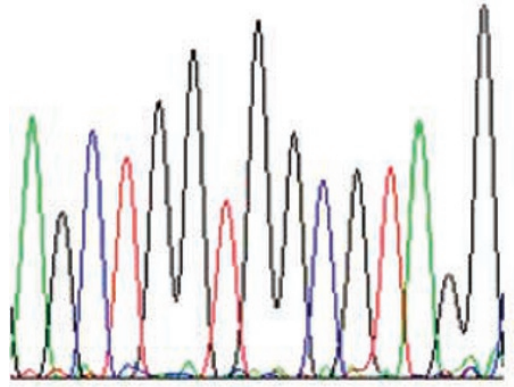

C $A G C T G G T G G C G T A G G$

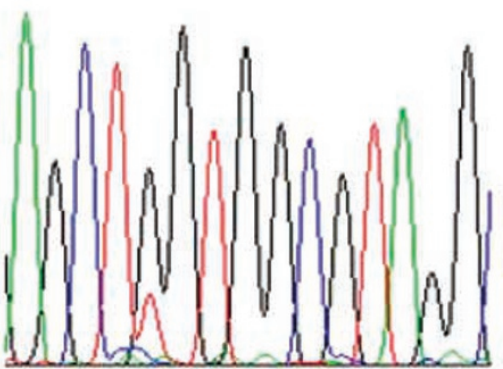

Metastasis

B $\quad A G C T G G T G G C G T A G G$

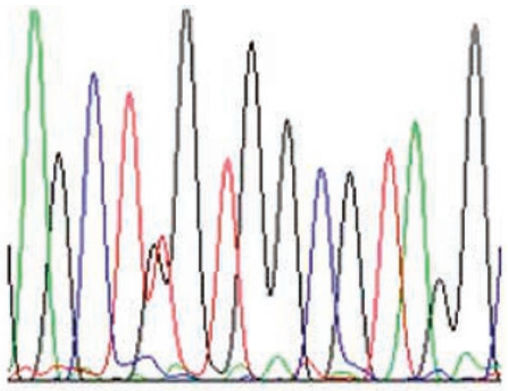

D $\quad A G C T G G T G G C G T A G G$

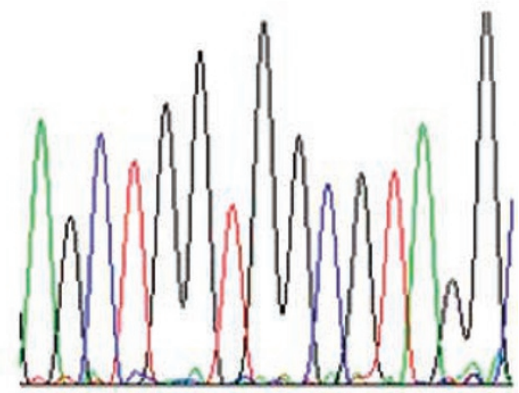

Figure 2 Representative examples of the K-Ras mutation status differences in primary tumour and related metastasis in mCRC. Wild-type K-Ras gene in the primary tumour (A) and GI2C mutation in the paired metastasis (patient no. 3) (B). K-Ras GI2C mutation in primary tumour (C) and K-Ras wild-type sequence in paired metastasis (patient no. 7) (D).

\section{DISCUSSION}

Epidermal growth factor receptor-targeted molecular therapies have acquired high relevance in the treatment of mCRC. However, the administration of anti-EGFR MoAbs (cetuximab and panitumumab) prolongs the survival rate of only a subset of mCRC patients (Ciardiello and Tortora, 2008). The identification of clinical and/or pathological features, or of molecular alterations able to predict sensitivity or resistance to anti-EGFR therapies, is therefore urgently needed. Currently, the prerequisites for cetuximab or panitumumab administration are represented by the EGFR immunohistochemical overexpression and, limited to panitumumab, by the absence of $K$-Ras mutations, according to FDA and EMEA guidelines (www.fda.org; www.emea.europa.eu). 

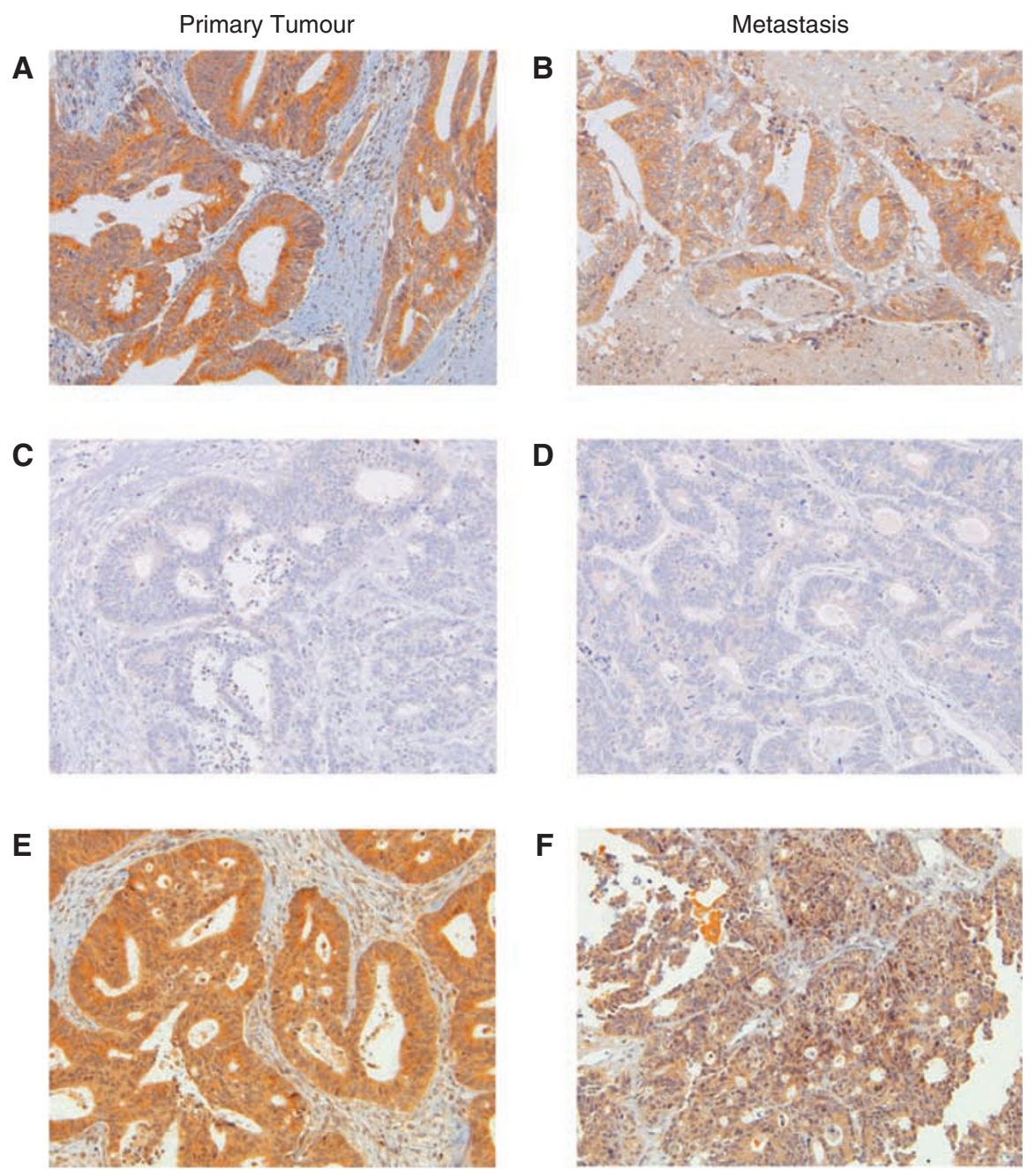

Figure 3 Representative examples of PTEN expression in primary tumour and related metastasis in mCRC. Equal PTEN immunohistochemical pattern between primary tumour $(\mathbf{A}$ and $\mathbf{C})$ and paired metastasis $(\mathbf{B}$ and $\mathbf{D})$ : PTEN-positive expression $(\mathbf{A}$ and $\mathbf{B})$ and PTEN-negative expression $(\mathbf{C}$ and $\mathbf{D})$. Normal PTEN expression in the primary tumour $(\mathbf{E})$ and reduction of PTEN immunodecoration in the metastatic lesion $(\mathbf{F})$.

Recent publications have clearly shown that the EGFR gene status and its downstream protein alterations (K-Ras and PTEN) may give additional information for a more accurate evaluation of antiEGFR treatment response (Lièvre et al, 2005; Moroni et al, 2005; Benvenuti et al, 2007; Cappuzzo et al, 2007; Di Fiore et al, 2007; Frattini et al, 2007; Khambata-Ford et al, 2007; Sartore-Bianchi et al, 2007; De Roock et al, 2008; Lièvre et al, 2008). However, even the evaluation of these additional molecular markers is not able to fully predict EGFR-targeted drug response. This fact could be explained by three putative mechanisms. (i) The use of inappropriate methodologies for the evaluation of a specific molecular marker. For instance, it has been demonstrated that neither EGFR protein expression evaluation by IHC nor EGFR mRNA expression by RT-PCR represents the gold standard method for the assessment of EGFR deregulation (Atkins et al, 2004; Langner et al, 2004; Vallböhmer et al, 2005; Kersting et al, 2006), whereas recent data suggest that EGFR gene status represents a better predictive marker of anti-EGFR therapy sensitivity (Lièvre et al, 2005; Moroni et al, 2005; Cappuzzo et al, 2007; Frattini et al, 2007; Sartore-Bianchi et al, 2007). (ii) The involvement of other not yet investigated genes. In this context, $B R A F$ may represent a novel predictive marker for anti-EGFR drug response (Benvenuti et al, 2007). (iii) the existence of different molecular patterns between primary tumour and paired metastatic lesion as predictive markers, so far, have been mostly evaluated in primary tumours disregarding alterations at metastatic sites. To shed light into this latter issue, earlier studies investigating primary tumours and paired metastases by IHC revealed different patterns of EGFR expression (McKay et al, 2002; Ooi et al, 2004; Scartozzi et al, 2004; Bralet et al, 2005; Italiano et al, 2005; Bibeau et al, 2006; Cappuzzo et al, 2007). Our data show that all primary tumours and metastases were positive, although they showed different staining intensities (data not shown).

The concept that primary tumour and distant metastasis may indeed show different molecular patterns is supported by the assessment of EGFR gene status by FISH. In our series, 12 cases (33\%) showed a discordant pattern. We found eight cases with a trend in favour of EGFR gene deregulation from primary tumour to metastasis and four cases with the opposite trend. These data reflect those obtained by Italiano et al (2006) in non-small-cell lung cancers. Several recent studies have demonstrated that patients showing EGFR gene deregulation defined either by Chr7 polysomy or EGFR gene amplification (cumulatively named CNG) could benefit from cetuximab treatment (Lièvre et al, 2005; Moroni et al, 2005; Cappuzzo et al, 2007; Frattini et al, 2007; SartoreBianchi et al, 2007). Two groups of patients are therefore of particular interest: patients with Chr7 disomy in primary tumour and EGFR gene CNG in paired metastatic lesions, and patients with 
the opposite pattern. The first group should not be addressed to anti-EGFR MoAb treatments based on the sole primary tumour evaluation, but eventually, it may benefit from these targeted therapies because of the presence of EGFR gene CNG in metastatic sites. The opposite may be valid for the second group of patients. Our results demonstrate only a moderate correlation between EGFR gene status in primary tumours and in corresponding metastatic sites $(\kappa=0.49, P=0.0002)$, and suggest that in patients with $\mathrm{mCRC}$, EGFR evaluation by FISH performed only in primary tumour may not be accurate enough to select candidates for a targeted therapy. The heterogeneity of EGFR gene status in neoplastic tissues obtained at different sites from the same patient is confirmed by our findings in lymph node metastasis. In fact, in patients with differences between primary tumour and related distant metastasis, the EGFR gene status pattern observed in lymph nodes was superimposable to primary tumours in six cases and to distant metastasis in two cases. Our data are in contrast with those of Cappuzzo et al (2007), who found that in 21 out of 22 cases the FISH pattern of EGFR gene status in primary tumour and distant metastatic sites is similar. This difference may be explained by environmental factors or by FISH technique and evaluation criteria. With respect to the latter point, it should be mentioned that a general consensus for EGFR gene status evaluation by FISH is currently lacking (Martin et al, 2008).

We extended the comparison between primary tumours and metastatic sites to the analysis of molecular markers belonging to EGFR downstream cascade, which have been previously identified as potentially predictive for anti-EGFR MoAb efficacy.

The analysis of primary tumours revealed $K$-Ras mutations in $43 \%$ of cases, BRAF mutations in $6 \%$ of cases and PTEN loss of expression in $21 \%$ of cases, in agreement with the earlier data concerning sporadic colorectal cancers (Rajagopalan et al, 2002; Frattini et al, 2005, 2007). We found a concordant pattern between primary tumours and related distant metastatic sites in 34 out of 37 cases for $K$-Ras, in all cases for BRAF and in 34 out of 38 cases for PTEN. These data show a good agreement between primary tumours and related metastasis for the deregulation of EGFR downstream members, in line with results available in the literature for K-Ras and BRAF (Artale et al, 2008; EtienneGrimaldi et al, 2008). However, it is important to underscore that the differences between the two sites may be clinically relevant for a given patient. In fact, patients without $K$-Ras or BRAF gene mutation, or with normal PTEN protein expression at primary tumour level, may become resistant if their metastases show alterations of these gene or proteins. By contrast, patients potentially resistant to the treatment may benefit from MoAb administration due to the absence of any alterations at metastatic level. The fact that primary tumour and related metastasis could be different in terms of gene mutations is confirmed by K-Ras analysis in non-small-cell lung cancer (Kalikaki et al, 2008).

\section{REFERENCES}

Andreyev HJ, Norman AR, Cunningham D, Oates J, Dix BR, Iacopetta BJ, Young J, Walsh T, Ward R, Hawkins N, Beranek M, Jandik P, Benamouzig R, Jullian E, Laurent-Puig P, Olschwang S, Muller O, Hoffmann I, Rabes HM, Zietz C, Troungos C, Valavanis C, Yuen ST, Ho JW, Croke CT, O’Donoghue DP, Giaretti W, Rapallo A, Russo A, Bazan V, Tanaka M, Omura K, Azuma T, Ohkusa T, Fujimori T, Ono Y, Pauly M, Faber C, Glaesener R, de Goeij AF, Arends JW, Andersen SN, Lövig T, Breivik J, Gaudernack G, Clausen OP, De Angelis PD, Meling GI, Rognum TO, Smith R, Goh HS, Font A, Rosell R, Sun XF, Zhang H, Benhattar J, Losi L, Lee JQ, Wang ST, Clarke PA, Bell S, Quirke P, Bubb VJ, Piris J, Cruickshank NR, Morton D, Fox JC, Al-Mulla F, Lees N, Hall CN, Snary D, Wilkinson K, Dillon D, Costa J, Pricolo VE, Finkelstein SD, Thebo JS, Senagore AJ, Halter SA, Wadler S, Malik S, Krtolica K, Urosevic N (2001) Kirsten ras mutations in patients with colorectal cancer: the 'RASCAL II' study. Br J Cancer 85: $692-696$
The clinical data concerning patients treated with EGFRtargeted therapies are in line with these hypotheses. Indeed, one patient did not respond to MoAbs by virtue of the absence of PTEN expression limited to the metastatic lesion in a context of a molecular profile proficient to MoAb response (EGFR CNG and no additional alterations in EGFR downstream pathways in both primary tumour and metastasis). In the other four patients showing discordant molecular profiles between primary tumour and metastasis and for whom clinical data were available, the additional presence of either $K-R a s$ or BRAF mutations at both sites predicted resistance to therapy.

It is important to highlight that we analysed mainly resection specimens (in 35 out of 38 primary tumours and in 23 out of 38 metastases), so that a discordant molecular pattern between primary tumour and paired metastasis due to a sample effect, although it cannot be excluded, is unlikely. Thus, the observed differences between primary tumour and metastasis may be explained by a trend in favour of gene or protein expression deregulation when the alteration is acquired by metastatic cells, whereas by a clone, present in a subgroup of primary tumour cells and characterised by an EGFR-independent metastatic phenotype, when the alteration is limited to primary tumour cells.

Finally, with respect to $K$-Ras, several additional issues are worthy to be discussed. First, we confirm that $K$-Ras and BRAF mutations are mutually exclusive (Rajagopalan et al, 2002). Second, besides the expected occurrence of G12D mutation (Frattini et al, 2007), we observed an unusual high frequency of G12A mutations, suggesting that this type of $K$-Ras alteration may confer a higher aggressive phenotype. Conversely, we found only one case with the $\mathrm{G} 12 \mathrm{~V}$ change, thus reinforcing the knowledge that this type of mutation may correlate with an indolent clinical course (Finkelstein et al, 1993; Frattini et al, 2007). However, as other studies showed discordant data (Andreyev et al, 2001), additional studies on this issue are clearly warranted.

To our knowledge, this is the first study concerning the analysis of EGFR protein expression and gene status, K-Ras and BRAF mutations, and PTEN protein expression in primary tumours as well as in lymph node and distant metastasis in the same cohort of mCRC patients. Our data, demonstrating different deregulation mechanisms of the EGFR pathways between primary tumours and related metastasis, deserve confirmation in larger and prospective studies. Nevertheless, the results may represent an important issue in the clinical practice and should be taken into account in designing future clinical trials based on anti-EGFR therapies.

\section{ACKNOWLEDGEMENTS}

This study was funded by Oncosuisse grant, OCS-01921-08-2006, and by Fondazione Ticinese per la Ricerca sul Cancro.
Artale S, Sartore-Bianchi A, Veronese SM, Gambi V, Sarnataro CS, Gambacorta M, Lauricella C, Siena S (2008) Mutations of KRAS and BRAF in primary and matched metastatic sites of colorectal cancer. J Clin Oncol 26: $4217-4219$

Atkins D, Reiffen KA, Tegtmeier CL, Winther H, Bonato MS, Störkel S (2004) Immunohistochemical detection of EGFR in paraffin-embedded tumor tissues: variation in staining intensity due to choice of fixative and storage time of tissue sections. J Histochem Cytochem 52: 890-893

Benvenuti S, Sartore-Bianchi A, Di Nicolantonio F, Zanon C, Moroni M, Veronese S, Siena S, Bardelli A (2007) Oncogenic activation of the RAS/ RAF signaling pathway impairs the response of metastatic colorectal cancers to anti-epidermal growth factor receptor antibody therapies. Cancer Res 67: 2643-2648

Bibeau F, Boissière-Michot F, Sabourin JC, Gourgou-Bourgade S, Radal M, Penault-Llorca F, Rochaix P, Arnould L, Bralet MP, Azria D, Ychou M 
(2006) Assessment of epidermal growth factor receptor (EGFR) expression in primary colorectal carcinomas and their related metastases on tissue sections and tissue microarray. Virchows Arch 449: 281-287

Bralet MP, Paule B, Adam R, Guettier C (2005) Loss of epidermal growth factor receptor expression in lymph node and liver metastases of colon carcinoma. J Clin Oncol 24: 5844-5845

Cappuzzo F, Finocchiaro G, Rossi E, Jänne PA, Carnaghi C, Calandri C, Bencardino K, Ligorio C, Ciardiello F, Pressiani T, Destro A, Roncalli M, Crino L, Franklin WA, Santoro A, Varella-Garcia M (2007) EGFR FISH assay predicts for response to cetuximab in chemotherapy refractory colorectal cancer patients. Ann Oncol 19: 717-723

Chung KY, Shia J, Kemeny NE, Shah M, Schwartz GK, Tse A, Hamilton A, Pan D, Schrag D, Schwartz L, Klimstra DS, Fridman D, Kelsen DP, Saltz LB (2005) Cetuximab shows activity in colorectal cancer patients with tumors that do not express the epidermal growth factor receptor by immunohistochemistry. J Clin Oncol 23: 1803-1810

Ciardiello F, Tortora G (2008) EGFR antagonists in cancer treatment. $N$ Engl J Med 358: 1160-1174

De Roock W, Piessevaux H, De Schutter J, Janssens M, De Hertogh G, Personeni N, Biesmans B, Van Laethem JL, Peeters M, Humblet Y, Van Cutsem E, Tejpar S (2008) KRAS wild-type state predicts survival and is associated to early radiological response in metastatic colorectal cancer treated with cetuximab. Ann Oncol 19: 508-515

Di Fiore F, Bianchard F, Charbonnier F (2007) Clinical relevance of KRas mutation detection in metastatic colorectal cancer treated by Cetuximab plus chemotherapy. Br J Cancer 96: 1166-1169

Etienne-Grimaldi MC, Formento JL, Francoual M, François E, Formento P, Renée N, Laurent-Puig P, Chazal M, Benchimol D, Delpero JR, Letoublon C, Pezet D, Seitz JF, Milano G (2008) K-Ras mutations and treatment outcome in colorectal cancer patients receiving exclusive fluoropyrimidine therapy. Clin Cancer Res 14: 4830-4835

Finkelstein SD, Sayegh R, Bakker A, Swalsky P (1993) Determination of tumor aggressiveness in colorectal cancer by K-ras-2 analysis. Arch Surg 128: $526-531$

Frattini M, Ferrario C, Bressan P, Balestra D, De Cecco L, Mondellini P, Bongarzone I, Collini P, Gariboldi M, Pilotti S, Pierotti MA, Greco A (2004) Alternative mutations of BRAF, RET and NTRK1, and absence of Ras mutation in papillary thyroid cancer. Oncogene 23: 7436-7440

Frattini M, Saletti P, Romagnani E, Martin V, Molinari F, Ghisletta M, Camponovo A, Etienne LL, Cavalli F, Mazzucchelli L (2007) PTEN loss of expression predicts cetuximab efficacy in metastatic colorectal cancer patients. Br J Cancer 97: 1139-1145

Frattini M, Signoroni S, Pilotti S, Bertario L, Benvenuti S, Zanon C, Bardelli A, Pierotti MA (2005) Phosphatase protein homologue to tensin expression and phosphatidylinositol-3 phosphate kinase mutations in colorectal cancer. Cancer Res 65: 11227

Italiano A, Saint-Paul MC, Caroli-Bosc FX, François E, Bourgeon A, Benchimol D, Gugenheim J, Michiels JF (2005) Epidermal growth factor receptor (EGFR) status in primary colorectal tumors correlates with EGFR expression in related metastatic sites: biological and clinical implications. Ann Oncol 16: 1503-1507

Italiano A, Vandenbos FB, Otto J, Mouroux J, Fontaine D, Marcy PY, Cardot N, Thyss A, Pedeutour F (2006) Comparison of the epidermal growth factor receptor gene and protein in primary non-small-cell-lung cancer and metastatic sites: implications for treatment with EGFRinhibitors. Ann Oncol 17: 981 - 985

Kalikaki A, Koutsopoulos A, Trypaki M, Souglakos J, Stathopoulos E, Georgoulias V, Mavroudis D, Voutsina A (2008) Comparison of EGFR and K-RAS gene status between primary tumours and corresponding metastases in NSCLC. Br J Cancer 99: 923-929

Kersting C, Packeisen J, Leidinger B, Brandt B, von Wasielewski $R$, Winkelmann W, van Diest PJ, Gosheger G, Buerger H (2006) Pitfalls in immunohistochemical assessment of EGFR expression in soft tissue sarcomas. J Clin Pathol 59: 585 - 590

Khambata-Ford S, Garrett CR, Meropol NJ, Basik M, Harbison CT, Wu S, Wong TW, Huang X, Takimoto CH, Godwin AK, Tan BR, Krishnamurthi SS, Burris III HA, Poplin EA, Hidalgo M, Baselga J, Clark EA, Mauro DJ
(2007) Expression of epiregulin and amphiregulin and K-ras mutation status predict disease control in metastatic colorectal cancer patients treated with cetuximab. J Clin Oncol 25: 3230-3237

Landis JR, Koch GG (1977) An application of hierarchical kappa-type statistics in the assessment of majority agreement among multiple observers. Biometrics 33: 363-374

Langner C, Ratschek M, Rehak P, Schips L, Zigeuner R (2004) Are heterogeneous results of EGFR immunoreactivity in renal cell carcinoma related to non-standardised criteria for staining evaluation? J Clin Pathol 57: $773-775$

Lièvre A, Bachet JB, Boige V, Cayre A, Le Corre D, Buc E, Ychou M, Bouché O, Landi B, Louvet C, André T, Bibeau F, Diebold MD, Rougier P, Ducreux M, Tomasic G, Emile JF, Penault-Llorca F, Laurent-Puig P (2008) KRAS mutations as an independent prognostic factor in patients with advanced colorectal cancer treated with cetuximab. J Clin Oncol 26: $374-379$

Lièvre A, Bachet JB, Le Corre D, Boige V, Landi B, Emile JF, Cote JF, Tomasic G, Penna C, Ducreux M, Rougier P, Penault-Llorca F, LaurentPuig P (2005) KRAS mutation status is predictive of response of cetuximab therapy in colorectal cancer. Cancer Res 66: 3992-3995

Martin V, Mazzucchelli L, Frattini M (2008) An overview of the EGFR FISH challenge in tumor pathology. J Clin Pathol [E-pub ahead of print]

McKay JA, Murray LJ, Curran S, Ross VG, Clark C, Murray GI, Cassidy J, McLeod HL (2002) Evaluation of the epidermal growth factor receptor (EGFR) in colorectal tumours and lymph node metastases. Eur J Cancer 38: $2258-2264$

Moroni M, Veronese S, Benvenuti S, Marrapese G, Sartore-Bianchi A, Di Nicolantonio F, Gambacorta M, Siena S, Bardelli A (2005) Gene copy number for epidermal growth factor receptor (EGFR) and clinical response to antiEGFR treatment in colorectal cancer: a cohort study. Lancet Oncol 6: 279-286

Ooi A, Takehana T, Li X, Suzuki S, Kunitomo K, Iino H, Fujii H, Takeda Y, Dobashi Y (2004) Protein overexpression and gene amplification of HER2 and EGFR in colorectal cancers: an immunohistochemical and fluorescent in situ hybridization study. Mod Pathol 17: 895-904

Personeni N, Fieuws S, Piessevaux H, De Hertogh G, De Schutter J, Biesmans B, De Roock W, Capoen A, Debiec-Rychter M, Van Laethem JL, Peeters M, Humblet Y, Van Cutsem E, Tejpar S (2008) Clinical usefulness of EGFR gene copy number as a predictive marker in colorectal cancer patients treated with cetuximab: a fluorescent in situ hybridization study. Clin Cancer Res 14: 5869-5876

Rajagopalan H, Bardelli A, Lengauer C, Kinzler KW, Vogelstein B, Velculescu VE (2002) Tumorigenesis: RAF/RAS oncogenes and mismatch-repair status. Nature 418: 934

Saal LH, Holm K, Maurer M, Memeo L, Su T, Wang X, Yu JS, Malmström PO, Mansukhani M, Enoksson J, Hibshoosh H, Borg A, Parsons R (2005) PIK3CA mutations correlate with hormone receptors, node metastasis, and ERBB2, and are mutually exclusive with PTEN loss in human breast carcinoma. Cancer Res 65: 2554-2559

Sartore-Bianchi A, Moroni M, Veronese S, Carnaghi C, Bajetta E, Luppi G, Sobrero A, Barone C, Cascinu S, Colucci G, Cortesi E, Nichelatti M, Gambacorta M, Siena S (2007) Epidermal growth factor receptor gene copy number and clinical outcome of metastatic colorectal cancer treated with panitumumab. J Clin Oncol 25: 3238-3245

Scartozzi M, Bearzi I, Berardi R, Mandolesi A, Fabris G, Cascinu S (2004) Epidermal growth factor receptor (EGFR) status in primary colorectal tumors does not correlate with EGFR expression in related metastatic sites implications for treatment with EGFR-targeted monoclonal antibodies. J Clin Oncol 22: $4772-4778$

Therasse P, Arbuck SG, Eisenhauer EA, Wanders J, Kaplan RS, Rubinstein L, Verweij J, Van Glabbeke M, van Oosterom AT, Christian MC, Gwyther SG (2000) New guidelines to evaluate the response to treatment in solid tumors. J Natl Cancer Inst 92: 205-216

Vallböhmer D, Zhang W, Gordon M, Yang DY, Yun J, Press OA, Rhodes KE, Sherrod AE, Iqbal S, Danenberg KD, Groshen S, Lenz HJ (2005) Molecular determinants of cetuximab efficacy. J Clin Oncol 23: $3536-3544$ 